\title{
Effects of Heat Stress on Working Populations when Facing Climate Change
}

\author{
Karin LUNDGREN ${ }^{1 *}$, Kalev KUKLANE ${ }^{1}$, Chuansi GAO ${ }^{1}$ and Ingvar HOLMÉR ${ }^{1}$ \\ ${ }^{1}$ Thermal Environment Laboratory, Institution of Design Sciences, Ergonomics and Aerosol Technology, Faculty \\ of Engineering, Lund University, Sweden
}

Received July 3, 2012 and accepted November 16, 2012

\begin{abstract}
It is accepted that the earth's climate is changing in an accelerating pace, with already documented implications for human health and the environment. This literature review provides an overview of existing research findings about the effects of heat stress on the working population in relation to climate change. In the light of climate change adaptation, the purpose of the literature review was to explore recent and previous research into the impacts of heat stress on humans in an occupational setting. Heat stress in the workplace has been researched extensively in the past however, in the contemporary context of climate change, information is lacking on its extent and implications. The main factors found to exacerbate heat stress in the current and future workplace are the urban 'heat island effect', physical work, individual differences, and the developing country context where technological fixes are often not applicable. There is also a lack of information on the effects on vulnerable groups such as elderly people and pregnant women. As increasing temperatures reduce work productivity, world economic productivity could be condensed, affecting developing countries in the tropical climate zone disproportionately. Future research is needed taking an interdisciplinary approach, including social, economic, environmental and technical aspects.
\end{abstract}

Key words: Heat stress, Occupational health, Climate change, Developing countries

\section{Introduction}

Climate change affects, either directly or indirectly, a wide range of sustainable development issues such as health, food security, employment, incomes and livelihoods, gender equality, education, housing and poverty. Existing policies and social protection systems are often inadequate to enhance resilience and adaptive capacity or to mitigate negative climate change impacts on employment. Arguably, climate change is also one of the largest environmental and health equity challenges as wealthy energy consuming nations are most responsible for the emissions that cause climate change, yet poor countries are

*To whom correspondence should be addressed.

E-mail: karin.lundgren@design.lth.se

(C)2013 National Institute of Occupational Safety and Health most at risk. Negative health effects from climate change stem from heat stress, communicable disease, air pollution, lack of food and water security, extreme weather events, malnutrition, stress, mental health issues, vulnerable shelter and population migration among others. Examples of climate-related hazards in the workplace include increased ambient temperature, air pollution, ultraviolet radiation exposure, extreme weather and vector-borne diseases such as malaria and expanded habitats ${ }^{1-3,31)}$.

Outdoor workers are the most vulnerable and the main sectors that are directly affected by climate change include agriculture, industry, fisheries, forestry, small and medium sized enterprises, indoor workplaces (for example without air conditioning), semi-outdoor workshops and construction work. Tourism, health, and finance/insurance sectors can be affected indirectly from for example extreme events ${ }^{4}$. 
Climate change can no longer be considered simply an environmental or developmental issue as it puts at risk the protection of human health and well-being.

In addition, while forecasts exist on the economic impact of climate change, the social impact on enterprises and workers, on employment and income, on working conditions, and on many other social dimensions is considerably less understood. Coping with climate change (adaptation) is already unavoidable due to past emissions of greenhouse gases. Thus, it is important to come up with solutions to reduce the vulnerability of workers and enterprises to the negative effects of climate change and to enhance the capacity at the individual and society levels to adapt, respond to and prepare for climate change. This literature review concentrates on the effects of heat stress on the working population with a focus on developing countries in relation to climate change. So far, climate change impacts related to heat stress have often been examined in relation to heat wave-mediated effects on the general population, but recognition is lacking that climate change may exacerbate occupational heat-related risks ${ }^{5)}$.

\section{Methods}

The extensive amount of information on heat stress made it necessary to have a strategic information search to find key articles. Climate change and occupational health is a highly multi-disciplinary field of study and requires scholarly information from a variety of sources. That is why the 'pearl picking' method was initially applied. This method uses one exceptionally useful article (often a review article) to track key articles in the field. The article chosen for the 'pearl picking' was: Kjellström, Holmér and Lemke: Workplace Heat Stress, Health and Productivity - an increasing challenge for low-and middle income countries during climate change ${ }^{6}$.

A thorough exploration of different databases and search engines was then carried out and several information retrieval tools were selected. Most were broad multidisciplinary platforms and databases covering a wide variety of journals and hence, more likely to have the articles desired. The information retrieval tools chosen were PubMed, Lund University's search engine Summons, Scopus, Google Scholar, Web of Science and the Science Citation Index ${ }^{7}$. Several search words were used such as 'occupational heat exposure', 'occupational heat stress', 'occupational heat strain', 'heat in/at workplace', 'work in the heat', 'occupational heat stress AND climate change' and the more broad search words 'heat stress'.
Relevant articles were then selected. An internal database and library was also used together with the International Labour Organization's Bookshelf on Occupational Safety and Health ${ }^{35)}$.

\section{Current Status}

\section{Climate change and its effects}

The Intergovernmental Panel on Climate Change's (IPCC) Forth Assessment Report (AR4) which came out in 2007 stated clearly that 'warming of the climate system is unequivocal, as is now evident from observations of increases in global average air and ocean temperatures, widespread melting of snow and ice and rising global average sea level'. Data records clearly show that the eleven years between 1995-2006, rank among the warmest in the instrumental record of global average surface temperature (since 1850). For the next two decades a warming of about $0.2^{\circ} \mathrm{C}$ per decade is projected for a range of future scenarios of emissions of greenhouse gases.

The AR4 reports that hot days, hot nights and heat waves have become and will become more frequent over most land areas ${ }^{8)}$. The continuous rise of absolute humidity in the lower troposphere has also been reported in many regions which add substantial implications for human thermal comfort and heat-related mortality and morbidity. In particular, this may add substantial risk in already humid countries, where a small increase in temperature can have profound consequences on heat stress ${ }^{9}$.

Heat waves are defined as 'extended periods of unusually high atmospheric related heat stress, which cause temporary modification in lifestyle and which may have adverse health consequences for a population, ${ }^{10)}$. Heat waves have already affected some aspects of human health, such as excess heat related mortality in Europe during the summer of $2003^{8)}$. This heat wave caused up to 70,000 deaths $^{11)}$. In France, data on causes of deaths showed that psychiatric, cardiovascular and pulmonary illnesses were associated with a higher risk of death in heat waves, while good social contacts in the community, the use of fans, air-conditioning and showers were associated with lower risk ${ }^{2}$. Additionally, deaths and illnesses caused by air pollution (e.g. ozone, particles) tend to increase during extremely warm weather ${ }^{12)}$. It is expected that European summer temperatures as high as those experienced in 2003 will be the norm by the middle of the century ${ }^{2}$. Responses to some recent extreme climate events reveal high levels of vulnerability in both developing and developed countries $^{8)}$. There is also increasing evidence of greater vulner- 
ability of specific groups such as poor and elderly people in all countries ${ }^{3)}$. High ambient temperature is a leading cause of weather related mortality in many regions of the world and heat exhaustion is the most common response to prolonged exposure to high outdoor temperatures ${ }^{3)}$.

As the world gets warmer, populations will acclimatize to some extent, raising the optimum temperature ${ }^{13)}$. The possible increased use of air conditioners, though, may hinder natural acclimatization and potentially increase the risk ${ }^{3,12)}$. Human populations have a great capacity to adapt physiologically, technologically, and by behavioural change, to gradual changes in climate. However, sudden changes in weather can have a significant impact on human physiology and therefore health. Assessing the impact of climate change on health is a complex task. There are often difficulties in obtaining data. Among them are the frequent interaction of climatic-environmental influences on health with factors such as level of economic development, the state of public health systems, and individual and population behaviour. Climate change will result in the increased prevalence, distribution, and severity of known occupational hazards such as heat stress and accidents although; there is no evidence of unique or previously unknown hazards. However, such a possibility should not be excluded, since there is potential for interactions of known hazards and new conditions leading to new hazards and risks. Climate change will affect living and working environments and create health threats for millions of people ${ }^{14)}$. For example, in the United States, 423 heatrelated fatalities among crop production workers occurred during 1992-2006 and this number was increasing over time. The heat related average annual death rate for these crop workers was 0.39 per 100,000 workers, compared with 0.02 for all U.S. civilian workers ${ }^{15)}$. Eventually, this could hamper economic and social development ${ }^{6,16)}$.

\section{Health effects and occupational heat exposure}

Health effects

The physiological basis for the effects of heat on humans is well understood ${ }^{17-25)}$ and extensive research have been done in military settings ${ }^{26-28)}$. Still, all is not yet understood of the pathophysiology of heat exhaustion and heat stroke. Human heat tolerance is the result of a series of adaptations that have been genetically encoded. Humans are born with a highly specialized complex of thermoregulatory sweat glands and a sensitive control system. For those groups living in hot environments, the employment of behavioural and cultural mechanisms has served as a buffer and it is clear that physiological adaptations are still of dominant importance in daily survival ${ }^{29)}$. A population has varying abilities to tolerate heat stress and it is increasingly recognized that social determinants and personal characteristics affect the vulnerability of people to heat exposure ${ }^{30)}$. Factors such as pre-existing disease, clothing, age, gender, ability for heat acclimatization, level of physical activity, and body size, can influence the health impact of heat stress. Also, the most powerful form of human thermoregulation is behavioural and includes measures such as less movement, clothing, seeking shade and opening windows ${ }^{29)}$.

When the ambient temperature reaches or exceeds the human core temperature of $37^{\circ} \mathrm{C}$, there are welldocumented physiological effects on the human body, posing risks to some organ systems and also making it progressively harder to work productively ${ }^{31)}$. As the core temperature begins to rise above its 'set-point' of $37^{\circ} \mathrm{C}$, skin blood flow increases and sweating is initiated.

At core temperatures beyond $38-39^{\circ} \mathrm{C}$, there is an increased risk of heat exhaustion and beyond these temperatures, heat stroke can occur with an eventual failure of the central nervous thermoregulatory system ${ }^{32)}$. Health consequences range from dehydration, injuries, and heat fatigue to a higher burden of respiratory and cardiovascular diseases, cataract, kidney failure, weakening of the immune system and death ${ }^{2)}$.

The body heat balance is determined by these six fundamental factors:

1. Air temperature

2. Radiant temperature

3. Humidity

4. Air movement ${ }^{6)}$

Non-climatic parameters:

5. Clothing

6. The metabolic heat generated by human physical activity $^{6}$

The human heat exchange with the environment is pictured in Fig. 1.

In addition, acclimatization and hydration status, body posture, clothing permeability and other factors affect this balance ${ }^{33)}$. An initial understanding of how environmental features can affect human heat tolerance may be gained through examination of the processes of heat transference between the body and the macro environment ${ }^{29)}$. These processes are radiation, conduction, convection, and evaporation at the skin surface and the lungs ${ }^{28)}$. Humans can maintain normal body (core and skin) temperatures within a wide range of environmental conditions, assuming heat transfer is not impaired. Heat dissipation occurs through 


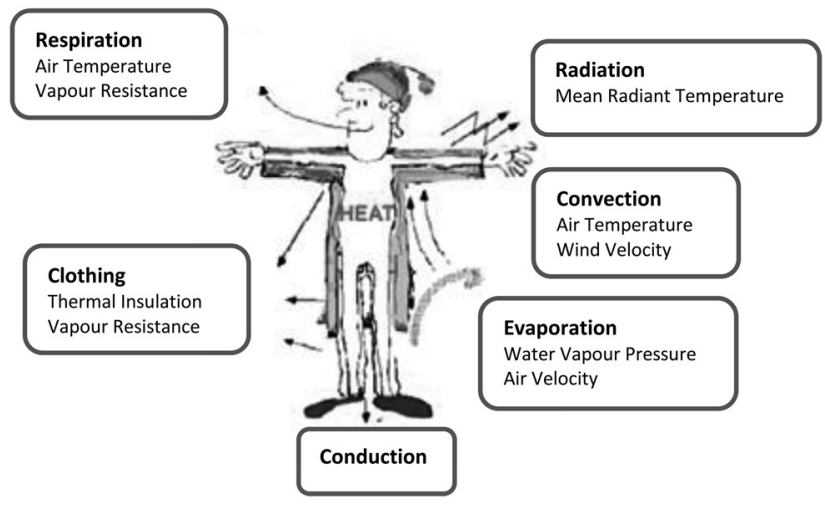

Fig. 1. Human heat exchange; Holmér, 2007.

dry heat loss (radiation and convection) and evaporative heat loss (sweating) ${ }^{34)}$. Acclimatization results in an increased sweat rate, leading to a lower core temperature and heart rate at the same work level and environmental heat load ${ }^{35)}$. Clothing affects the transfer of heat from and to the body through resistance to air movement and water, permeability and ventilation. The insulating characteristics influence the transfer of heat ${ }^{36)}$.

Connected to the human heat exchange is the heat balance equation, through which the balance between heat production and heat exchange can be calculated (can be modified to account for clothing):

$$
\begin{gathered}
S=(M-W)-\left(H_{\text {res }}+E+R+C+K\right) \\
\mathrm{S}=\text { body heat storage } \\
\mathrm{M}=\text { metabolic heat production } \\
\mathrm{W}=\text { external mechanical work } \\
\mathrm{H}_{\text {res }}=\text { respiratory heat exchange } \\
\mathrm{E}=\text { evaporative heat exchange } \\
\mathrm{R}=\text { radiative heat exchange } \\
\mathrm{C}=\text { convective heat exchange } \\
\mathrm{K}=\text { conductive heat exchange }
\end{gathered}
$$

The largest source of heat results from metabolic heat production which adds to the heat stress in hot environments. The evaporation of sweat is extremely effective and therefore becomes more and more critical with increasing environmental temperature. Given the importance of sweat evaporation it is not surprising that wind velocity and air humidity are critical environmental factors in hot conditions. If the humidity is high, sweat is still produced but evaporation is reduced which reduces the cooling effect ${ }^{35)}$. The thermoregulatory response can be powerful and effective but it can also incur a strain on the body which can lead to heat illness ${ }^{28)}$. Heat disorder occurs for one or more of three reasons: dehydration/lack of ac- climatization, lack of proper appreciation of the dangers of heat, and accidental and unforeseeable circumstances leading to exposure. Many deaths are attributed to neglect and lack of consideration ${ }^{28)}$. Heatstroke has a high fatality rate and even nonfatal heatstroke can lead to long term effects. Sweating imposes the greatest strain on the body. Severe dehydration (at a water loss of about $6 \%$ of body weight) may lead to heat exhaustion and circulatory collapse ${ }^{35)}$. Together with water loss, sweating produces a loss of electrolytes, mainly sodium and chloride, but also to a lesser degree magnesium, potassium etc. If the sweat loss is replaced by water, this may cause cramps due to the malfunction of nerves and muscles. Dehydration of over $3 \%$ of body weight should always be treated with water and electrolyte replacement ${ }^{35}$.

\section{Occupational heat exposure}

Workers in the outdoor occupations with high physical load are most at risk for severe heat exposure. Also at high risk are workers required to wear semipermeable or impermeable protective clothing and/or personal protective equipment (PPE) that severely impedes heat exchange through evaporation ${ }^{36,37)}$.

Heat can cause workers to take off protective clothing due to discomfort, putting the worker at high risk for dangerous exposure and injury ${ }^{38)}$. There are also possible heat implications for indoor workers in buildings without air conditioning or proper ventilation systems in warm countries. Most of the heatstroke deaths reported have been associated with occupational exposure at construction sites, agricultural settings, and hot industrial jobs requiring heavy work. The increased cardiovascular load experienced during heat stress compromises the capacity for physical work ${ }^{39}$ ). Cognitive and physical performance decrements can occur at hyperthermic and/or dehydration levels lower than those causing heat injuries ${ }^{34)}$. Furthermore, socioeconomic factors such as income and urbanization can compound the adverse health outcomes from heat stress on workers as it may indirectly cause psychological distress due to reduced work productivity, lost income, and disrupted daily social activity ${ }^{40)}$. Outdoor work is the most problematic and fatalities due to heat stress are associated with warm nights, hot days and hard physical work. Total physiological burden and the potential susceptibility to heat disorders will be much higher if heat stress continues during off-duty hours through work at second jobs, strenuous leisure activities, or living in unremittingly hot quarters. In addition, nutritional status and hydration may reflect patterns of eating and drinking, which may 
also change with season or religious observances ${ }^{35}$. Heat exhaustion is most often preceded by dehydration and is usually associated with unacclimatized workers. Heat stroke in otherwise normal and healthy people results from a combination of excessive heat exposure and physical work $^{36)}$. Fluid requirements generally depend on work rate, the ambient climatic conditions, and on individual physiological and biochemical characteristics.

Implementation of strategies to maintain adequate hydration is the single most important intervention in the management of work in heat. Where this cannot be achieved, it is necessary to set dehydration limits of the percentage lost in body weight (e.g. a $2 \%$ decrease translates into 1-4 litres of liquid ${ }^{28)}$ ). Detailed limiting values for work in hot environments can be found in international standards such as ISO7933 for acclimatized and non-acclimatized workers ${ }^{41)}$. Yet, it is found that even if water is readily available, men working in the heat will drink less than that lost through perspiration, referred to by researchers as 'voluntary dehydration, ${ }^{28,29)}$. Therefore, workers in hot environments must also be educated regarding the importance of drinking enough water while working and continuing generous rehydration during off-duty hours ${ }^{35,42)}$. Another intervention could be to implement traditional work-rest schedules developed for centuries to deal with heat, instead of simply implementing an industrial model, or to develop individual workrest schedules. Urban workers may also be exposed to additional heat stress as a result of the urban 'heat island effect' of the urban built environments ${ }^{1)}$.

The urban heat island effect

In 2007, the world's population living in towns and cities surpassed $50 \%$ for the first time in history and this share is continuously growing; by 2050 it could be as high as two thirds ${ }^{2}$. Built-up areas influence the absorption and reflection of solar radiation, the ability to store heat, the absorption and emittance of long wave radiation, winds and evapotranspiration (the discharge of water from the earth's surface to the atmosphere). The built environment is also characterized by human activities affecting the climate, such as the heating and cooling of buildings, motor traffic and industrial production.

These activities release heat and moisture but also pollute the air, which affects incoming and outgoing radiation $^{43)}$. A limited number of trees and vegetation in urban areas also decreases the capacity to cool the air through transpiration (the loss of water by evaporation in terrestrial plants $)^{3)}$. The 'urban heat island effect' is thus the heat

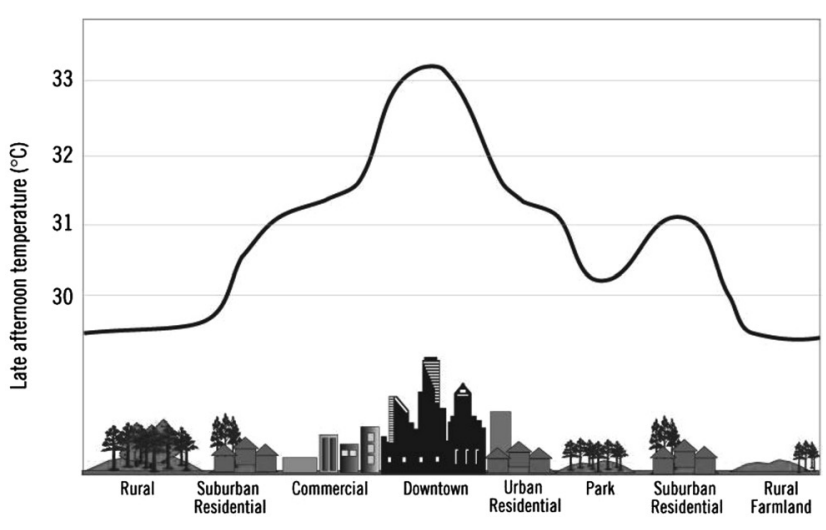

Fig. 2. Heat island effect profile; US EPA, 2012 ${ }^{45}$.

absorption in cities and refers to the difference in temperatures measured inside and outside the city ${ }^{44)}$. This is primarily a nocturnal phenomenon, as during daytime, urbanrural temperature differences are usually smaller because of the relatively high thermal capacity and energy storage of urban surface materials. After sunset, the energy stored is released causing an additional warming. The severity of the urban heat island decreases with increasing emissivity (emission of energy by radiation) from the sky (e.g. due to increased cloud cover) and with increased wind speed. These elevated temperatures can increase the magnitude and duration of heat waves. Some large cities, such as Mexico City, have shown a heat-island effect measuring an increase of up to $4-5^{\circ} \mathrm{C}$ in comparison to the surrounding rural areas ${ }^{43}$. Below is The US Environmental Protection Agency's schematic view of the heat island effect profile (Fig. 2).

\section{Individual aspects}

Individual factors such as physical fitness and health status plays a fundamental role in heat tolerance ${ }^{28)}$. When working in heat, people with the highest risk are those with small body size, overwheight, elderly and people with medical conditions such as cardivascular diseases, diabetes, skin, liver, kidney and lung problems and pregnancy. Additional factors affecting heat tolerance include intake of alcohol, caffeine and nicotine ${ }^{46}$. Individual differences include the effects of age, gender, body morphology, disability, aerobic capacity, acclimatization, state of health, clothing and personal protection equipment ${ }^{47)}$. How ethnic origin and cultural differences, including human behaviour, influence heat tolerance, is not fully understood ${ }^{28)}$. Knowledge of the mechanisms behind subjective differences is important for risk assessment ${ }^{44)}$ and the next sections will explore these aspects further. 


\section{Children and the Elderly People}

Children and elderly people are likely to be more sensitive to over-heating, in particular if they are working. An excess death rate due to heat illness has been reported among elderly people, infants and children ${ }^{44)}$. This is partly due to physiological difficulties in regulating heat, and restricted mobility, which decreases the ability to access fluids when needed ${ }^{48)}$. Children are included in this review on occupational health as child labour is still common in many countries (this is against international conventions such as the International Labour Organizations Convention nr. 182 on the worst forms of child labour and nr.138 on minimum age ${ }^{49)}$ ). Children may also be present in workplaces, and babies may sometimes be strapped on the back of their mothers as they are working. An excess death rate due to heat illness has been reported among infants and children during heat waves compared with adults ${ }^{50)}$.

Babies have relatively large heads, large surface area to mass ratios, high blood flows and limited sweating capacity, as their system of thermoregulation is still developing. It is also likely that thermo-neutral temperatures occur within a narrower range of conditions ${ }^{28)}$. The limited ability to thermoregulate makes small children more at risk of dehydration ${ }^{44)}$. Infants will experience a more rapid rise in body temperature and may not be able to respond by removing themselves from the stress environment or pursuing other behavioural defences ${ }^{51 \text { ) }}$.

The reason why elderly people are particularly at such an increased risk of thermoregulatory deficits is not a new question, yet still unsolved ${ }^{52)}$. Generally, body mass, size, and composition changes with age in addition to the decline of homeostatic responses and the regulation of blood pressure ${ }^{24)}$. These changes usually take place around the age of $80^{53)}$ and as retirement age is increasing in many countries, or in some, workers continue working until they are unable to do so. As a result, examining the effects of heat stress on elderly people at work is essential. Available data suggest that heat tolerance is reduced in older people as they have lower metabolic rates and aerobic capacity (oxygen uptake) due to sedentary lifestyles (although core temperature remains the same $)^{28)}$. Due to a reduced activity level, old people tend to expose themselves less to physical strain which leads to a loss of heat acclimatization, reduced ability to transport heat from the body core to the skin, and a lower cardiovascular stability ${ }^{35)}$. Longer periods of hot weather, especially when little relief is given at night have hit primarily the older population. The percentage of people with illnesses and disabilities also increases with age ${ }^{54)}$.
On the other hand, in a study by Kenney and Havenith in 1993, it was found that when fit healthy older subjects are matched with younger subjects of the same gender, size and body composition, metabolic rate, acclimation state and hydration level, the thermal tolerance is less a function of chronological age than of functional capacity and physiological health status. As a result, what is not so clear is whether aging per se is associated with poor heat tolerance, or whether alterations in other factors associated with the aging process play a larger role ${ }^{55)}$.

\section{Men and women}

Men and women have slightly different physiology, endocrinal physiology and body characteristics; one example being men having on average greater body size, weight and strength. In general, yet with large individual differences, women have a larger surface to mass ratio, which implies that women are more prone to heat loss. On the other hand, women have a higher whole body and subcutaneous fat content than men, which in turn increases insulation. Women are known to have colder skin at distal areas, despite the increased body fat content relative to men. Part of this effect can be attributed to reproductive hormones and the menstrual phase. In general, relative to men, the thermoneutral zone of women is shifted upward (the temperature range at which the person feels 'comfortable') ${ }^{56)}$. When comparing the sexes, it has been observed that women tolerate humid heat better as females are superior in suppressing excess sweating and therefore conserve body water. Both sweating and vasoconstriction thresholds are $0.3-0.5^{\circ} \mathrm{C}$ higher in women than men, even during the first days of the menstrual cycle. Differences are even greater in between menstruations ${ }^{53)}$. Males have higher maximal sweat rates, which may enhance tolerance for extremely hot and dry environments ${ }^{35}$.

In contrast, some studies have found that there is no or little difference between men and women in either metabolic heat production or in heat exchange by radiation, convection or evaporation. The observed superior capacity of men for sustained exercise in desert heat is rather related to their higher aerobic capacity and not to a difference in capacity for thermoregulation. Differences in heart rate between men and women are mainly dependent on individual differences, fitness and stress level rather than differences in thermoregulation ${ }^{57)}$.

Although in a study by Havenith in 2005, females had generally higher core temperatures, skin temperature, heart rates, blood pressure, and set points for sweating, in comparison to males ${ }^{57)}$. Moreover, Witterseh et al., 2004, 


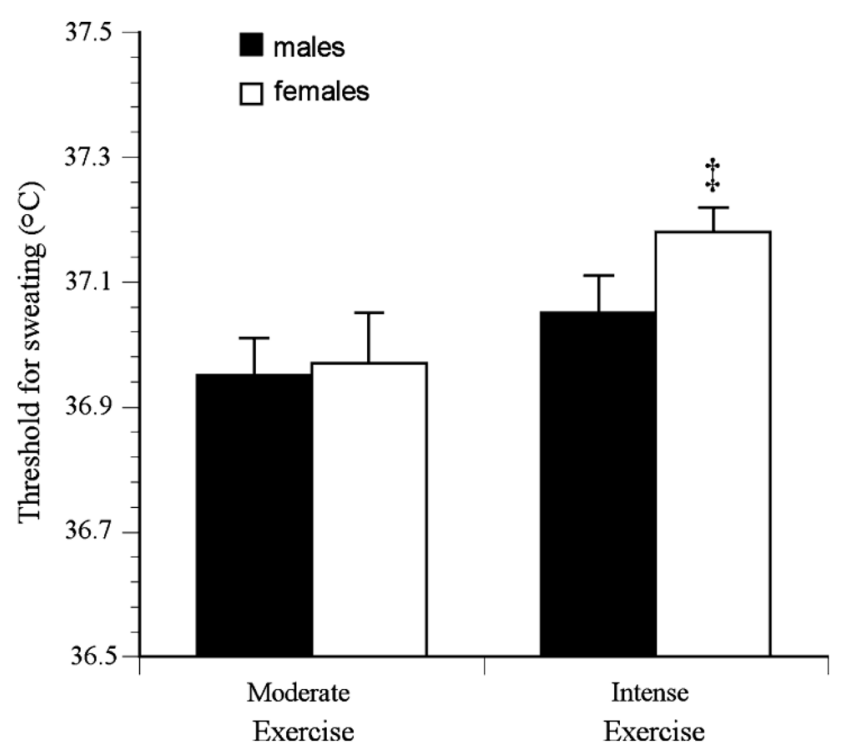

Fig. 3. Gender differences in onset of sweating during exercise, Kenney et al., 200759).

found that the effects of heat stress on performance seem to be more adverse for males than for females ${ }^{58)}$ and Kenney et al., 2007 found that females show a greater increase in the core temperature onset threshold for sweating in both moderate and intense exercise (Fig. 3$)^{59)}$.

Two specific female processes do affect thermoregulation: the menstrual cycle and menopause, although the effect of the menstrual cycle at rest (a higher core temperature in the postovulatory phase) seems to be almost absent during heat exposure. Postmenopausal hot flashes and night sweating provide anecdotal evidence that thermoregulation is affected by oestrogen withdrawa ${ }^{57)}$. The effect of pregnancy on women's heat tolerance is not clear, but altered hormone levels, added weight, reduced adaptive capacity and the increased circulatory demands of the foetus on the mother may increase the susceptibility to fainting. Severe maternal hyperthermia (over-heating) due to illness appears to increase the incidence of foetal malformation $^{35)}$. In a study by Hartgill et al., 2011, it was found that human temperature regulation is altered in pregnancy. Maternal core temperature was at its highest in the first trimester but fell during pregnancy with its lowest point 3 months post-delivery and persisted until 6 months after delivery in breast-feeding women. The causes of the delayed return to normal temperature can currently only be speculated on ${ }^{60)}$. It also appears that women, especially older women, are more at risk, in both relative and absolute terms, of dying in a heat wave ${ }^{44)}$. Whether or not this is due to women generally living longer is not clear.
Ethnicity

Few studies were found in relation to ethnicity and heat tolerance. It is suggested that people living in high altitudes, such as Tibet, in the hot climates of Africa, or in the cold environments of Lapland may have developed special physiological capabilities for coping with extremes. Such adaptations might even be genetic such as the Saharan Touareg, with tall slender bodies that maximize the surface cooling area in proportion to the amount of body tissue that produces heat.

Some adaptations, though, may well be acquired during one's lifetime rather than being genetic ${ }^{61)}$. In one study by Meese, 1983, it was found that Afro-American subjects show a performance reduction with falling temperature when compared to Caucasians ${ }^{62}$. In a recent case control study it was found that African-Americans had the highest risk of heat-related mortality, and that Caucasians had a higher risk than Hispanics ${ }^{48}$. On the other hand, this might be more related to socio-economic status than ethnic origin. It has also been found that people from New Guinea have lower sweat rates than Nigerians, showing some genetic factors in variations of sweat rate ${ }^{28)}$. There is little evidence, though, of inherent or genetic differences in response to heat stress and all humans appear to function as tropical animals. The ability of humans to live and work in a range of thermal conditions rather reflects adaptation through complex behaviour and the development of housing, clothing and technology. Apparent ethnic differences probably relate more to body size, individual life history and nutritional status rather than to inherent traits ${ }^{35)}$.

\section{Productivity loss and economic impact}

Productivity is strongly dependent on thermal conditions, in particular during physically demanding work ${ }^{63)}$. Studies of the influence of high ambient temperature on performance have examined variables such as reaction time, tracking and vigliance, as well as memory and mathematical calculations ${ }^{61)}$. When the body is hot, vasodilation (a widening of blood vessels) enhances ease of body movement although sweating may affect grip, cause distraction due to discomfort, fatigue and psychological strain. Thermal conditions can affect output, accident rates, behavioural and cognitive performance ${ }^{28)}$.

The results of many studies indicate that changes in temperature of a few degrees can significantly influence performance in several tasks including typewriting, factory work, signal recognition, time to respond to signals, learning performance, reading speed and comprehension, multiplication speed, and word memory. It is estimated 
that approximately a 7\% increase in productivity is present in a workplace maintained at the population-average neutral temperature of between $20-24^{\circ} \mathrm{C}^{64-66)}$. It is also estimated that productivity is affected after about one hour of moderate physical work in temperatures above $32^{\circ} \mathrm{C}^{61)}$. In an analysis of Thai industrial workers by Tawatsupa in 2009 , it was found that $\sim 60 \%$ of the workers reported loss of working capacity in the heat, and about $20 \%$ were more vulnerable to heat illnesses during the summer months ${ }^{40}$. In a study by Kjellström et al., 2009, it was found that by the 2080s, the greatest absolute losses of population based labour work capacity (in the range 11 to $27 \%$ ) will be seen under the IPCC A2 scenario in Southeast Asia, Andean and Central America, Eastern Sub-Saharan Africa and the Caribbean. The A2 scenario assumes a high population growth and medium rapid economic development and therefore represents a moderately 'high' emissions scenario $^{68)}$

A natural reaction of a working person to heat is to reduce physical activity, which reduces the body's internal heat production. An outcome of this preventive reaction is reduced hourly work capacity and economic productivity during the exposure to heat. As a result, the worker's action to prevent ill health will lower productivity and a loss of daylight work hours will occur. In the long term, this will affect individual, local, national and regional economic productivity.

An enterprise can compensate for this by carrying out heat sensitive work during the cooler night hours of the hot season or by scheduling such work in the cooler season, but as climate change progresses the duration of cooler periods will be shortened. In addition, some work has to be carried out during daylight ${ }^{67)}$. Without adaptation, the economic losses of reduced labour productivity relative to baseline could potentially be up to $20 \%$ of the gross domestic product (GDP) ${ }^{68)}$.

\section{Developing country context}

The proportion of the world's population living in the tropical climate zone, with normal daytime air temperatures exceeding $30^{\circ} \mathrm{C}$, is estimated to be about $40 \%$. Conditions are in some countries worsened by intense solar radiation and high humidity ${ }^{11)}$. Most tropical countries are developing countries and most are experiencing rapid urbanization ${ }^{43)}$. The impacts of climate change on vulnerable employment, working poverty (income below the poverty line), youth and women, wage losses and working conditions may be exacerbated. This hits the most vulnerable even harder because of their exposure and least adaptive capacity ${ }^{69)}$. Despite this, few comprehensive assessments on the effects of climate change on health have been completed in low-income countries, and none in Africa ${ }^{11)}$.

Occupational health and safety is one of the basic rights that workers are being denied in many developing countries $^{70)}$. In general, developing countries also have higher occupational injury fatality rates compared to developed countries. Many workers lack work security and are paid according to output; as a result, workers have to work longer hours to reach production targets.

When working in heat, which limits the ability to produce, stress and serious mental and physical health problems may become a negative outcome. In addition, on the side of paid work, many workers also engage in water collection, firewood collection, residence building and repair, small-scale agriculture, fishing, cooking and so on. These tasks can sometimes be more hazardous than formal employment, and add to the heat strain and exhaustion $^{71)}$. Moreover, commuting to and from work is a daily source of heat exposure for many people. Urban growth is extensive in these regions making populations especially vulnerable to climate change ${ }^{11)}$.

Agriculture is generally a big employer in the developing world. Commonly, farm workers work are at high risk as they work under high pressure, perform extended hours of work in heat and high humidity, suffer dehydration and often do not have sufficient knowledge regarding prevention from heat exposure. Additionally, cultural aspects and malnutrition, poverty and stress add to the high risk environment ${ }^{72)}$. For example, fatality due to heat accounted for $11 \%$ of farm accidents in India during the heat wave of 1998-1999 ${ }^{73)}$. Another example is in Central America, where authorities are overwhelmed by the high prevalence of chronic kidney disease (CKD). CKD is a worldwide public health problem and knowledge about the prevalence or incidence of early-stage CKD is scarce. One hypothesis is that heavy workloads in a hot climate lead to chronic dehydration, partly causing the problem ${ }^{74)}$.

It has been found that this disease has a high prevalence in sugarcane workers where they are under constant heat stress. It may be partially due to chronic dehydration related to working conditions ${ }^{75)}$.

In developing countries people may be more or less acclimatized although health and nutritional status, access to drinking water and widespread precaurious work are decisive factors ${ }^{39)}$. In addition, small and medium sized enterprises (SME's) are the most common employer. It is estimated that SME's have a $33 \%$ greater accident rate than companies with 200 employees and more. It is 
therefore essential to increase the likelihood of improvements of the working conditions in SME's ${ }^{76}$. In a study by Ayyappan et al. in 2009, multiple locations and industries were measured around India (400 measurements). The study showed that many processes even in organized large-scale industries have yet to control heat stress related hazards adequately ${ }^{5}$. Additional examples from industries in Thailand and Tanzania have shown that the workplaces frequently exceed international guideline values for heat ${ }^{40)}$, such as ISO7243 and ISO7933, which describes appropriate heat stress indices and guidelines ${ }^{41,77)}$. These guidelines, however, have been assessed in developed countries and therefore are not fully applicable in warm developing countries where workers are more acclimatized $^{78)}$.

\section{Preventative and control measures}

Despite uncertainty in climate change impacts, it is assumed that humans will have to adapt to warmer temperatures. Strategies to reduce the effects of future climate change involve an iterative risk management process that includes both mitigation (reducing emissions of greenhouse gases) and adaptation (coping strategies). Whether or not humans will be able to adapt to future increasing heat is uncertain, although humans already inhabit various climatic spaces ${ }^{8)}$.

Some risks can be managed by adaptation policies, the success of which will depend on the speed and extent of climate change, the sustainability of measures, and the level of global cooperation to implement measures to support and protect vulnerable regions and populations ${ }^{4)}$. Generally, the aim of adaptation to climate change is to reduce vulnerability and increase resilience to impacts. The heat wave of 2003 in Europe suggests that adaptation is not occurring successfully even in developed countries and public health efforts in response to heat focus primarily on reactive measures rather than long-term adaptation. The underlying perception that heat is not a high priority prevents the uptake of relevant information to avert heat stress. On the other hand, working practices for hot environments are well established (for example NIOSH, $1986^{79)}$ ), including the use of appropriate heat stress indices, acclimatization programmes, and the importance of water replacement, although, lessons seem to have to be re-learnt ${ }^{28)}$.

The main factors for the protection against danger from heat at the workplace are to safeguard from and control the source of the heat ${ }^{40)}$. Heat stress controls can also be divided into two broad categories: general and specific.
General controls include thermal audit methods and personal monitoring using heart rate and internal body temperature measuring equipment ${ }^{28)}$. General controls should be implemented anytime there is a reasonable potential for heat stress on the job and are applicable across all heat stress jobs. Specific controls are directed to individual jobs and include specific training, heat stress hygiene practices and medical surveillance ${ }^{36)}$. A heat stress assessment follows the traditional hierarchy of hazards control, being in the order of elimination, substitution, engineering controls, administrative controls and finally, personal protection.

Overall, there is a large variation in cost, capability and constraints with the different systems ${ }^{36)}$.

\section{Engineering control measures}

Engineering solutions include those of risk alert systems, response plans, water delivery, portable shade structures, water based cooling, air based systems, decreased clothing insulation (e.g. through smart textiles), ventilated clothes, cooling centres, air conditioning, personal cooling systems (e.g. ice vest) protective clothing, wearing white and loose-fitted clothing, etc. ${ }^{72)}$. Active cooling systems are widely available such as liquid cooling and air cooling garments ${ }^{28)}$. Active cooling systems include external connections to air or liquid supplies such as ventilated cooled air and circulated liquid cooling ${ }^{80)}$. A practical solution is that of increasing ventilation in clothing by using air permeable clothes that are designed to increase possibilities for ventilation or by using fans for active ventilation. Passive cooling systems utilize phase change materials (PCMs) (e.g. ice, frozen gel, salt, wax) in vests and clothing. PCMs are latent heat storage materials and absorb or release heat when they change phases, such as from solid to liquid (heat of fusion), and back to solid (heat of crystallization). Therefore, a PCM has two types of thermal effects: a cooling effect when it melts and a heating effect when it solidifies $^{81,82)}$. Wearable personal cooling integrated with PCMs has the advantage of cooling the human body's micro-environment in contrast to stationary personalized or building cooling, thus providing greater mobility and saving energy ${ }^{80)}$. Selection of the optimum active clothing system will depend upon the requirements of the task and consideration should be given to work organization and design. Any effective cooling system should be placed where a heat exchange occur, for example, by the neck, wrists and under arms, and should not restrict thermoregulation.

For instance, when wearing a cooing vest running up a hill, the metabolic cost of carrying the vest might offset the 
benefit of cooling. The vest can also restrict the evaporation of sweat, add weight, increase the metabolic rate, and so on. For a sedentary task in a hot environment, however, it may be useful if it does not cause too much cooling ${ }^{28)}$. Moreover, these technical fixes may not be applicable to developing countries, especially in small businesses where room for investment is scarce. For instance, the price of a cooling vest ranges between $\$ 200-300$, which is why preventative and managerial methods may be more appropriate in a developing country context. On the other hand, all workplaces around the world should follow the widely accepted traditional hierarchy of controls mentioned ear$\operatorname{lier}^{36)}$

Dehumidifying and cooling the indoor air may reduce heat stress and increase productivity in hot and humid indoor work places in developing countries. However, many work situations are such that air conditioning is not feasible and fans are not sufficient when the heat exposure is very high. In addition, air conditioning is costly as it uses plenty of energy, which also adds to the climate change problem. Moving the person to a cooler area and cooling off the person's body may be an essential preventive action ${ }^{40)}$. An innovative solution is a solar-powered system for supplying dry air in offices, providing a lowcost alternative to traditional air conditioning in hot and humid regions. The system can also be produced using local skills and resources, representing a low-cost alternative to high-tech air conditioning ${ }^{83)}$.

\section{Preventative control measures}

Preventative interventions include design of urban areas, trees in industrial areas ${ }^{83)}$, design of housing and workplaces to reduce heat exposure, increase shading, and public and occupational health programmes that protect individuals at risk, among others ${ }^{40)}$. One general control is that of work-rest regimes. However, determining safe work-rest regimens based on heat stress criteria is challenging. Relying on the self-pacing of the workers is not recommended especially when the task has an urgent character or involves productivity incentives. Studies have shown that self-paced work-rest regimes were poorly related to physiological parameters ${ }^{84)}$. Self-chosen rest periods are too short to dissipate heat ${ }^{38)}$. Therefore, selfpaced workers must be associated with close supervisory surveillance or predetermined work-rest schedules, which may constitute a better solution ${ }^{85}$. As a response to challenges in a warmer world, development of acclimatization procedures, hazard communications, early warning systems and surveillance, and increased emphasis on prevention through design can present vital solutions ${ }^{1)}$. Finally, education and training of workers and employers is essential for effective risk management. Measures that reduce thermal stress without compromising performance and productivity, together with being a low cost option, are more likely to be accepted ${ }^{23)}$.

\section{Conclusion and Future Research Needs}

On the basis of the reviewed articles, it can be summarized that heat stress has been researched extensively in the past. However, in the contemporary context of climate change, information is lacking on the extent of future heat stress and its consequences, especially in an occupational setting. It was also found that heat stress is often an overlooked problem and that lessons seem to have to be relearnt. The main factors found to exacerbate heat stress in the current and future workplace are the urban 'heat island effect', physical work, individual differences, and the developing country context where technological fixes and certain control measures are often not applicable. There is also a lack of information on the effects on vulnerable groups such as elderly people and pregnant women.

Occupational health and safety is one of the basic rights that workers are being denied in many developing countries. In addition to this, as work productivity reduces with increasing temperatures, world economic productivity will be condensed, affecting developing countries disproportionately as most of these already are located in warm climates. To address these current and future occupational health problems, sustainable solutions must be interdisciplinary and take into account the social, economic, environmental and technical aspects of the problem. Both mitigation and adaptation measures should be considered, sometimes in combination and including both preventative and control solutions, to achieve multiple benefits. Capacity building such as education and awareness, and involvement on all levels of society is needed to address this.

From the review it became apparent that research is needed in these areas:

- Occupational heat stress in different countries and ways of dealing with it; studies are especially needed in Africa.

- Heat island effects on workplaces in urban areas.

- Current adaptation practices in warm countries.

- Heat stress control options and possible sustainable solutions (low cost).

- Analysis of future productivity losses due to heat stress and economic analysis. 
- Social and health effects of heat stress.

- Effects on vulnerable groups such as young and elderly people, women, pregnant women, and poor people.

\section{References}

1) Schulte PA, Chun H (2009) Climate change and occupational safety and health: establishing preliminary framew. J Occup Environ Hyg 6, 542-54. [Medline]

2) WHO Climate Change and Occupational Health. http:// www.ituc-csi.org/IMG/pdf/Occupational_Health_and Climate_Changes_presentation_Sept27.pdf. Accessed February 10, 2012.

3) Ford D, Berrang-Ford L (2011) Climate change adaptation in developed nations: from theory to practice, Quebec. Springer, Dordrecht.

4) Nilsson M, T Kjellström (2010) Climate change impacts on working people: how to develop intervention Policies. 3 (5774).

5) Ayyappan R, Sankar S, Rajkumar P, Balakrishnan K (2009) Work-related heat stress concerns in automotive industries: a case study from Chennai, India. Global Health Action 2, 58-64.

6) Kjellström T, Holmér I, Lemke B (2009) Workplace heat stress, health and productivity - an increasing challenge for low-and middle income countries during climate change. Global Health Action 2.

7) Moed H (2005) Citation analysis in research evaluation. University of Amsterdam, Amsterdam.

8) IPCC (2007) IPCC Forth Assessment Report: climate change. Cambridge University Press, Cambridge.

9) Willett KM, Sherwood S (2012) Exceedance of heat index thresholds for 15 regions under a warming climate using the wet-bulb globe temperature. Int J Climatol 32, 161-77. [CrossRef]

10) White-Newsome JL, et al. (2012) Climate change and health: indoor heat exposure in vulnerable populations. Environ Res 112, 20-7. [Medline] [CrossRef]

11) Costello A, Abbas M (2009) Managing the Health Effects of Climate Change. Lancet 373, 1693-733. [Medline] [CrossRef]

12) Wasim Yahia M (2012) Microclimate and Thermal Comfort of urban Spaces in Hot Dry Damascus, in Faculty of Engineering., Lund University, Lund.

13) Berrang-Ford L, Ford JD, Paterson J (2011) Are we adapting to climate change? Glob Environ Change 21, 25-33. [CrossRef]

14) Hanna EG, Spickett JT (2011) Climate change and human health: building Australia's adaptation capacity. Asia Pac J Public Health 23 (suppl 2) 7S-13S. [Medline] [CrossRef]

15) CDC (2008) Heat-related deaths among crop workers United States, 1992-2006, 1017-18, C. Centres for Disease and Prevention, (Eds).

16) Auliciens A (1992) Greenhouse warmed Europe: thermoregulatory criteria for future indoor climate management. Int J Biometeorol 36, 201-9. [CrossRef]

17) Weiner JS, Van Heyningen RE (1952) Salt losses of men working in hot environments. Br J Ind Med 9, 56-64. [Medline]

18) Ladell WSS (1955) The effects of water and salt intake upon the performance of men working in hot and humid environments. J Physiol 127, 11-46. [Medline]

19) Burton AC (1933) The application of the theory of heat flow to the study of energy metabolism. J Nutr, 497-533.

20) Budd GMA (1974) A field survey of thermal stress in new guinea villagers. Philos Trans R Soc Lond B Biol Sci 268, 393-400. [Medline] [CrossRef]

21) Bell CR, Watts AJ (1971) Thermal limits for industrial workers. Br J Ind Med 28, 259-64. [Medline]

22) Fernandez RHP (1980) Healthcare of people at work: controlling persons working in heat. Occup Med (Chic Ill) 30, 40-2. [CrossRef]

23) Hales JRS, Richard DAB (1987) Heat Stress - Physical Exertion and Environment. Excerpta Medical 525, Amsterdam.

24) Hellon RF, Lind AR, Weiner JS (1956) The physiolocigal reactions of men of two age groups to a hot environment. J Physiol 133, 118-31. [Medline]

25) Ramsey JDA (1983) Effects of workplace thermal conditions on safe work behaviour. J Safety Res 14, 105-14. [CrossRef]

26) Schrier RW, et al. (1970) Renal, metabolic and and circulatory responses to heat and exercise - Studies in military recruits during summer training, with implications for acute renal failure. Ann Intern Med 73, 213-23. [Medline]

27) US Department of the Army and the Air Force (2003) Heat stress control and heat causality management. Technical Bulletin. USDAAF, Washington DC.

28) Parsons K (2003) Human thermal environments, 2nd Ed., Taylor and Francis, New York.

29) Hanna JM (1983) Human heat tolerance: an anthropological perspective. Annu Rev Anthropol 12, 259-89. [CrossRef]

30) Hollowell DR (2010) Perceptions of, and reactions to, Environmental heat: a brief note on issues of concern in relation to Occupational Health. Global Health Action, 3.

31) Bennett CM, McMichael AJ (2010) Non-heat related impacts of climate change on working populations. Global Health Action 3.

32) Jay O, Kenny GP (2010) Heat exposure in the Canadian workplace. Am J Ind Med 53, 842-53. [Medline]

33) Kampmann B, Bröde P, Fiala D (2011) Physiological responses to temperature and humidity compared to the assessment by UTCI, WGBT and PHS. Int J Biometeorology.

34) O'Brien C, Blanchard LA, Cadarette BS, Endrusick TL, Xu X, Berglund LG, Sawka MN, Hoyt RW (2011) Methods of evaluating protective clothing relative to heat and cold stress: thermal manikin, biomedical modeling, and 
human testing. J Occup Environ Hyg 8, 588-99. [Medline] [CrossRef]

35) International Labour Organization (1998) Safe Work Bookshelf. ILO, Geneva.

36) Bernard TE, Dukes- Dobos FN, Ramsey JD (1994) Evaluation and control of hot working environments. Part II: the scientific basis (knowledge base) for the guide. Int $\mathrm{J}$ Ind Ergon 14, 129-38. [CrossRef]

37) Bernard TE (1999) Heat stress and protective clothing: and emerging approach from the United States. Ann Occup Hyg 43, 321-7. [Medline]

38) Wästerlund DS (1998) A review of heat stress research with application to forestry. Appl Ergon 29, 179-83. [Medline] [CrossRef]

39) Holmér I (2009) Heat and cold stress, in OSH for development, Elgstrand K and Petersson NF (Eds.), Royal Institue of Technology, Sweden.

40) Tawatsupa B (2010) The association between overall Health, psychological distress, and Occupational Heat Stress among a large national cohort of 40, 913 Thai workers. Global Health Action 3.

41) ISO7933. http://www.iso.org/iso/iso_catalogue/catalogue tc/catalogue_detail.htm?csnumber $=37600$. Accessed May 16, 2012.

42) Miller VS, Bates GP (2010) Hydration, hydration, hydration. Ann Occup Hyg 54, 134-6. [Medline] [CrossRef]

43) Johansson E (2006) Urban design and outdoor thermal comfort in warm climates. Studies in Fez and Colombo, in housing development and management. Lund University, Lund.

44) Kovats RS, Hajat S (2008) Heat stress and public health: a critical review. Annu Rev Public Health 29, 41-55. [Medline] [CrossRef]

45) US Environmental Protection Agency Reducing Urban Heat Islands: Compendium of Strategies Urban Heat Island Basics. 2012. http://www.epa.gov/heatisld/resources/pdf/ BasicsCompendium.pdf. Accessed October 5, 2012.

46) Gavhed D, Holmér I (2006) Det Termiska Klimatet på Arbetsplatsen 2006, Arbetslivsinstitutet, Stockholm (in Swedish).

47) Brake DJ, Bates GP (2002) Limiting metabolic rate (thermal work limit) as an index of thermal stress. Appl Occup Environ Hyg 17, 176-86. [Medline] [CrossRef]

48) Hattis D, Ogneva-Himmelberger Y, Ratick S (2012) The spatial variability of heat-related mortality in Massachusetts. Appl Geogr 33, 45-52. [CrossRef]

49) International Labour Organization (2012) I. International Programme on the Elimination of Child Labour (IPEC); ILO Conventions and Recommendations. http://www.ilo. org/ipec/facts/ILOconventionsonchildlabour/lang-en/index. htm. Accessed May 16, 2012.

50) Tsuzuki-Hayakawa K (1995) Thermoregulation during heat exposure of young children compared to their mothers. Eur J Appl Physiol Occup Physiol 72, 12-7. [Medline]
[CrossRef]

51) Keim SM, Guisto JA, Sullivan JB (2002) Environmental thermal stress. Ann Agric Environ Med 9, 1-15. [Medline]

52) Van Someren EJW (2006) Thermolregulation and Aging. American Journal of Physiology - Regulatory. Integr Comp Physiol 292, 99-102. [CrossRef]

53) Sessler DI (2008) Temperature monitoring and perioperative thermoregulation. Anesthesiology 109, 318-38. [Medline] [CrossRef]

54) Havenith Ga (1995) Age predicts cardiovascular, but not thermoregulatory responses, to humid heat stress. Eur J Appl Occup Physiol 70, 88-96. [Medline] [CrossRef]

55) Kenney LW, Havenith G (1993) Thermal physiology of the elderly and handicapped. J Therm Biol 18, 341-4. [CrossRef]

56) Kingma B, Frijns A, van Marken Lichtenbelt W (2012) The thermoneautral zone: implications for metabolic studies. Front Biosci E4, 1975-85.

57) Havenith G (2005) Temperature regulation, heat balance and climatic stress. Extreme Weather Events and Public Health Responses 7, 69-80.

58) Witterseh T, Wyon DP, Clausen G (2004) The effects of moderate heat stress and open-plan office noice distraction on SBS symptoms and of the performance of office work. Indoor Air 14, 30-40. [Medline] [CrossRef]

59) Kenny GP, Olley J (2007) Evidence of a greater onset threshold for sweating in females following intense exercise. Eur J Appl Physiol 101, 487-93. [Medline] [CrossRef]

60) Hartgill TW, Bergersen TK, Pirhonen J (2011) Core body temperature and the thermoneutral zone: a longitudinal study of normal human pregnancy. Acta Physiol (Oxf) 201, 467-74. [Medline] [CrossRef]

61) Bell P, et al. (2005) Environmental Psychology, 5th Ed. Taylor and Francis, London.

62) Meeser GB, Kok R, Lewis MI (1982) The effect of moderate thermal stress on the potential work performance of factory workers-An interim report. Energy Build 4, 289-94. [CrossRef]

63) Lloyd, EL (1994) ABC of sports medicine: temperature and performance II: Heat. BMJ 309, 587. [Medline] [CrossRef]

64) Fisk WJ (2000) Health and productivity gains from better indoor environments and their relationships with building energy efficiency. Annu Rev Energy Environ 25, 537-66. [CrossRef]

65) Wyon DP (2004) The effects of indoor air quality on performance and productivity. Indoor Air 14, 92-101. [Medline] [CrossRef]

66) Balakrishnan K, Ramalingam A, Dasu V, Stephen JC, Sivaperumal MR, Kumarasamy D, Mukhopadhyay K, Ghosh S, Sambandam S (2010) Case studies on heat stress related perceptions in different industrial sectors in southern India. Glob Health Action 3, 1-11. [Medline]

67) Kjellström T (2011) Occupational heat exposure - a forgotten threat from climate change, in climate change and 
occupational health expert meeting. Lund University, Lund.

68) Kjellström $T$ (2009) The direct impact of climate change on regional labour productivity. Arch Environ Occup Health 64, 217-27. [Medline] [CrossRef]

69) International Labour Office (2011) Towards an ILO approach to climate change adaptation, E. Sector. ILO, Geneva.

70) Ahasan MR (1999) Work related problems in metal handling tasks in Bangladesh: obstacles to the development of safety and health measures. Ergonomics 42, 385-96. [Medline] [CrossRef]

71) Hogstedt C, Kjellström T (2009) A global perspective on $\mathrm{OSH}$, in $\mathrm{OSH}$ for development, Elgstrand $\mathrm{K}$ and Petersson NF (Eds.), Royal Institute of Technology, Stockholm.

72) Schenker M (2011) Occupational heat-related illness among agricultural workers, in climate change and occupational health expert meeting. Lund University, Lund.

73) Nag PK, Nag A, Ashtekar SP (2007) Thermal limits of men in moderate to heavy work in tropical farming. Ind Health 45, 107-17. [Medline] [CrossRef]

74) Torres C, et al. (2010) Decreased kidney function of unknown cause in Nicaragua: a community-based survey. Am J Kidney Dis 55, 485-96. [Medline] [CrossRef]

75) Crowe J, van Wendel, de Joode B, Wesseling C (2009) A pilot field evaluation on heat stress in sugarcane workers in Costa Rica: what to do next? Global Health Action 2.

76) Malchaire J (1999) Strategy for evaluation and prevention of risk due to work in thermal environments. Ann Occup Hyg 43, 367-76. [Medline]
77) ISO7243 (1989) http://www.iso.org/iso/iso_catalogue/ catalogue_tc/catalogue_detail.htm?csnumber $=13895$. Accessed May 16, 2012.

78) Holmér I (2010) Climate change and occupational heat stress. Global Health Action 3.

79) National Institute of Occupational Safety and Health (1986) Criteria for a recommended standard: occupational exposure to hot environments, 86-113, NIOSH, Atlanta.

80) Gao C, Kuklane K, Wang F, Holmér I (2012) Personal cooling with phase change materials to improve thermal comfort from a heat wave perspective. Indoor Air 22, 523-30. [CrossRef]. [Medline]

81) Gao C, Kuklane K, Holmér I (2011) Cooling vests with phase change materials: the effects of melting temperature on heat strain alleviation in an extremely hot environment. Eur J Appl Physiol 111, 1207-16. [Medline] [CrossRef]

82) Gao C, Kuklane K, Holmér I (2010) Cooling vests with phase change material packs: the effects of temperature gradient, mass and covering area. Ergonomics 53, 716-23. [Medline] [CrossRef]

83) Gunnarsen L, Santos AMB (2002) Reduced heat stress in offices in the tropics using solar powered drying of the Supply Air. Indoor Air 12, 252-62. [Medline] [CrossRef]

84) Kjellström T, Lemke B, Otto M (2011) Climate change, occupational heat stress, and impacts on health and Productivity in Africa. Afr Newsl Occup Health Saf 21, 44.

85) Mairiaux P, Malchaire J (1985) Workers self-pacing in hot conditions: a case study. Appl Ergon 16, 85-90. [Medline] [CrossRef] 